\title{
Aportes de la genética de la conservación al estudio de los mamíferos neotropicales: revisión y análisis crítico
}

\author{
Maximiliano Nardelli ${ }^{\varpi_{\&}}$ Juan I. Túnez \\ Grupo de Investigación en Ecología Molecular (GIEM), Departamento de Ciencias Básicas, Universidad Nacional de Luján. \\ Luján, Argentina.
}

\begin{abstract}
Resumen. Si bien todos los seres vivos modifican su entorno, nuestra especie ha adquirido la capacidad de hacerlo a una escala espacio-temporal superlativa. Como resultado de la industrialización y del uso de nuevas tecnologías, el impacto antrópico ha ido en aumento en los últimos siglos, lo que causó la disminución de los tamaños poblacionales o la extinción de numerosas poblaciones silvestres. En este sentido, desde el campo de la genética de la conservación, en las últimas décadas se realizaron diversos esfuerzos para aportar conocimientos nuevos que contribuyan a la conservación de poblaciones, especies y hábitats. Las propiedades de los distintos marcadores moleculares han permitido estudiar la variabilidad genética de las especies y cómo esa variabilidad se estructura en las poblaciones y define las llamadas Unidades de Manejo, que son unidades genéticas cuyo nombre deriva de actividades extractivistas. En este artículo revisamos y analizamos críticamente los esfuerzos científicos en el área de la genética de la conservación realizados entre 2006 y 2015 en pos de la conservación de los mamíferos del Neotrópico. También criticamos el concepto de Unidad de Manejo y analizamos las perspectivas a futuro en el campo de la genética de la conservación de los mamíferos neotropicales.
\end{abstract}

[Palabras clave: biología de la conservación, fauna neotropical, especies amenazadas, marcadores moleculares]

\begin{abstract}
Aвstract. Contributions of conservation genetics to the study of neotropical mammals: review and critical analysis. Although all living beings modify their environment, our species has acquired the ability to do so on a superlative space-time scale. As a result of industrialization and the use of new technologies, the anthropic impact has been increasing in the last centuries, causing the decrease in population sizes or the extinction of numerous wild populations. In this sense, from the field of conservation genetics, diverse efforts have been made in the last decades in order to provide new knowledge that contributes to the conservation of populations, species and habitats. The properties of the different molecular markers have allowed studying the genetic variability of the species and how it is structured in the populations, defining the so-called Management Units, genetic units whose name derives from extractivist activities. In this article we perform a review and critical analysis of the scientific efforts in the area of conservation genetics carried out between the years 2006 and 2015 for the conservation of mammals of the Neotropics, criticize the concept of Management Unit and analyze future perspectives in the field of conservation genetics of neotropical mammals.
\end{abstract}

[Keywords: conservation biology, neotropical fauna, threatened species, molecular markers]

\section{INTRODUCCIÓN}

Todos los seres vivos modifican su entorno durante su ciclo de vida, y realizan los intercambios de materia y energía necesarios para mantener sus funciones vitales. Nuestra especie ha adquirido la capacidad de modificar el ambiente en una escala espaciotemporal mucho mayor a la del resto de los seres vivos (Vitousek et al. 1997). Los avances en la Era de la Modernidad, de la mano de la Revolución Industrial y el cambio del modelo de producción, mejoraron la calidad y la expectativa de vida de una parte de la población humana. Sin embargo, todos estos avances son sustentados por el extractivismo, la generación de subproductos y residuos tóxicos o contaminantes, la acumulación de desechos y el uso, abuso y despilfarro de fuentes de materia y energía a tasas no renovables. En la década de 1940 comienza a implantarse el paradigma del desarrollismo, que reduce la idea de desarrollo a un proceso lineal de crecimiento económico (Gudynas and Acosta 2011). Con una mayor demanda de materias primas, mayor industrialización, la formación de las grandes urbes y la estimulación al consumismo, el impacto sobre la naturaleza no tardó en hacerse evidente. En este sentido, el modelo desarrollista prometía que el crecimiento económico y tecnológico mitigaría los impactos ambientales (Gudynas 2003). Hoy podemos reconocer que esta afirmación es una de las promesas incumplidas del modelo (Rodríguez Rodríguez and Sanhueza Martínez 2014). 
El resto de las especies del planeta sufren de forma directa o indirecta la degradación del ambiente generada por las actividades humanas. La fragmentación del hábitat, la disminución de los tamaños poblacionales, el cambio climático, la antropización de los ambientes, los cambios en el uso del suelo, la extracción de recursos naturales y la introducción de especies exóticas, en combinación con factores estocásticos, ponen en riesgo la supervivencia de distintas especies y el equilibrio en las comunidades y los ecosistemas (Primack 2002; Periago et al. 2015). De hecho, nos encontramos en una era de pérdida de biodiversidad sin precedentes (Bertorelle et al. 2009). En línea con esto, se vienen llevando adelante innumerables proyectos de investigación en el área de la biología de la conservación, con especial énfasis en aquellas especies en riesgo de extinción y en zonas de alto impacto antrópico (Costa et al. 2005; Rodríguez et al. 2005; Harvey et al. 2008; Bertorelle et al. 2009; Barletta et al. 2010; Viglizzo et al. 2011; DinizFilho et al. 2013; Ghimire and Pimbert 2013; Güneralp and Seto 2013; Courchamp et al. 2014; Jiménez-García et al. 2014; Menon 2014; Selig et al. 2014; Pierson et al. 2015).

Poco tiempo después de surgir la biología de la conservación como disciplina, los científicos encontraron en la genética de poblaciones y en los marcadores moleculares herramientas muy útiles para interpretar las dinámicas y el estado de conservación de las poblaciones (Hartl and Clark 1998; Frankham et al. 2002; Bertorelle et al. 2009). En este sentido, se pudieron estimar distintos parámetros poblacionales como la variabilidad genética, las relaciones filogeográficas, el grado de fragmentación y la estructura y flujo génico, entre otros (Avise 2004), dando origen a una nueva disciplina denominada genética de la conservación. Dicha disciplina se encarga del estudio de los factores genéticos que afectan al riesgo de extinción de las especies y de proponer regímenes de manejo genético para minimizar dicho riesgo (Frankham et al. 2002). Los efectos de un tamaño poblacional pequeño sobre la variabilidad genética son la mayor preocupación de la genética de la conservación, ya que las especies en peligro presentan poblaciones poco abundantes o con tasas de crecimiento negativas. Las poblaciones pequeñas sufren los efectos de la endogamia o la pérdida de diversidad genética, lo que resulta en un aumento del riesgo de extinción. En consecuencia, el mayor objetivo del manejo genético es minimizar esta pérdida de diversidad genética (Frankham et al. 2002).

La región neotropical contiene una gran porción de la biodiversidad mundial (Mittermeier et al. 1998), con $\sim 37 \%$ del total de las plantas con semilla (90.000-110.000 especies) (Antonelli and Sanmartín 2011), alrededor de 1490 especies de mamíferos terrestres, 74 especies de mamíferos marinos residentes o avistados en las cercanías de la costa, 4037 especies de aves entre residentes y migratorias, 2441 especies de reptiles y 1865 especies de anfibios (Ojasti and Dallmeier 2000; Perrin et al. 2009; IUCN 2015).

Los objetivos de este estudio son: a) realizar una revisión de los manuscritos publicados entre los años 2006 y 2015 en los que se utilizaron herramientas genéticas para analizar problemáticas relacionadas a la conservación de poblaciones naturales de mamíferos neotropicales, analizando críticamente los esfuerzos científicos llevados a cabo; b) poner en discusión el concepto de Unidades de Manejo en estudios de conservación, y c) ensayar perspectivas a futuro y realizar algunas recomendaciones en torno a las metodologías a emplear en este campo del conocimiento.

\section{ORganizaCión Y METODOLOGÍA DEL ESTUDIO}

El presente trabajo se divide en 5 secciones. En primer lugar, realizamos un resumen del estado actual de la conservación de los diferentes órdenes de mamíferos del Neotrópico. En las secciones segunda y tercera resumimos los principales aportes de la biología molecular a la conservación de la fauna silvestre e identificamos aquellos órdenes para los cuales la información genética todavía es escasa. Para ello, realizamos una búsqueda exhaustiva de estudios que hicieron aportes significativos a la conservación de los mamíferos del Neotrópico, en los que se utilizó como herramienta algún tipo de marcador molecular mitocondrial o nuclear. En total revisamos 180 artículos publicados en la última década (2006-2015). Además, y con el fin de poder cuantificar los esfuerzos científicos en el campo de la genética de la conservación, en dicho período desarrollamos tres índices "ad hoc" que calculamos para cada uno de los 15 órdenes de mamíferos analizados. a) Índice PPE (publicaciones por especie): número de publicaciones sobre las 
especies que componen un orden dividido por el número de especies en dicho orden. Este índice evidencia los esfuerzos científicos realizados en cada uno de los 15 órdenes analizados, independientemente de la categoría de conservación de las especies que los componen; b) índice PEA (publicaciones sobre especies amenazadas): número de publicaciones sobre las especies amenazadas en un dado orden dividido por el número de especies amenazadas en dicho orden. Para el cálculo de este índice consideramos como amenazadas a aquellas especies categorizadas por la UICN como Vulnerables (VU), En Peligro (EN) o En Peligro Crítico (CR). Este índice evidencia los esfuerzos científicos realizados en aquellas especies consideradas como amenazadas, y c) índice IDI (índice de interés): es el cociente entre el PPE y el PEA. Valores menores a 1 en el IDI evidencian un mayor esfuerzo en el estudio de las especies del orden independientemente del estado de conservación, mientras que valores mayores a 1 evidencian un mayor esfuerzo en el estudio de especies amenazadas.

Luego, en la cuarta sección, revisamos el concepto de Unidad de Manejo. Por último, analizamos las perspectivas a futuro y las limitaciones de las técnicas utilizadas frecuentemente en estudios de genética de la conservación.

\section{ESTADO ACTUAL DE LOS MAMÍFEROS NEOTROPICALES}

La región neotropical es, probablemente, la más biodiversa del planeta. Sin embargo, esta vasta expresión de vida se ve amenazada dado que muchas de las especies que habitan la región se encuentran en peligro de extinción o presentan tasas de crecimiento negativas a causa de factores de origen antrópico. De hecho, Ceballos et al. (2015) sugieren que este fenómeno es parte de un proceso de extinción masiva de vertebrados que está ocurriendo a nivel global y cuya causa principal es la relación que mantiene la sociedad moderna con el ambiente.

El Neotrópico presenta 1564 especies de mamíferos, agrupadas en 15 órdenes. Vale aclarar que el número exacto de especies es difícil de estimar ya que el estatus de especie o subespecie para algunas de ellas depende del criterio utilizado por los investigadores expertos en los diferentes taxones. El número de especies que componen cada uno de estos 15 órdenes presentes en la región es muy variable, y se observa, por ejemplo, una única especie en el orden Microbiotheria y más de 800 en el orden Rodentia (Figura 1). Todas estas especies han sido incluidas en alguna de las seis categorías de estado de conservación de la UICN (Ceballos et al. 2015) (Tabla 1). Asimismo, cuando se analiza en cada uno de los órdenes el número de especies que presenta cierto grado de amenaza, es decir, aquellas que se encuentran categorizadas como Vulnerables, En Peligro o En Peligro Crítico, los números varían entre 138 especies para el orden Rodentia y $<3$ especies en órdenes como Cingulata, Microbiotheria, Paucituberculata, Perissodactyla, Pilosa y Sirenia (Figura 1). En cuanto al porcentaje de especies amenazadas en cada orden, Perissodactyla y Sirenia son aquellos que presentan el mayor porcentaje (el 100\%) de las especies que los componen

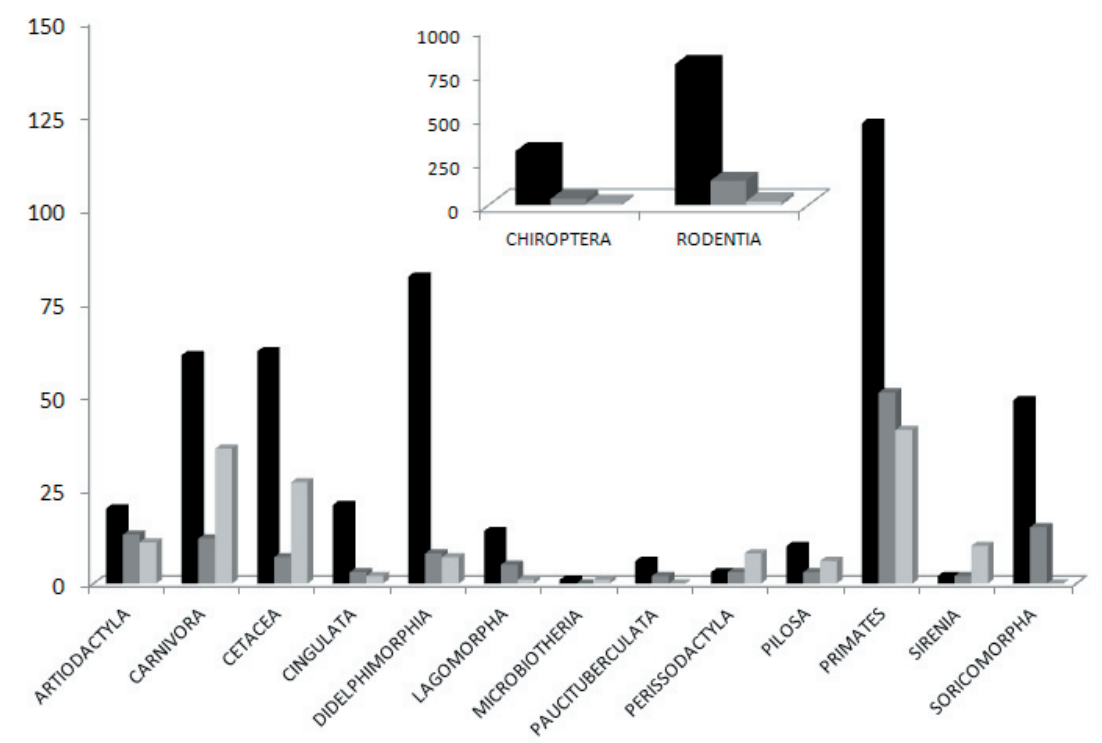

Figura 1.Númerodeespecies y especies amenazadas que componen cada uno de los 15 órdenes de mamíferos del Neotrópico. Color negro: número de especies; gris oscuro: número de especies amenazadas; gris claro: número de artículos publicados en el orden.

Figure 1. Number of species and threatened species that compose each of the 15 orders of mammals of the Neotropics. Color black: number of species; dark gray: number of threatened species; light gray: number of articles published in the order. 
Tabla 1. Número de especies (porcentajes entre paréntesis) incluidas en las diferentes categorías de la UICN para los 15 órdenes de mamíferos presentes en el Neotrópico. DD: datos Insuficientes; LC: preocupación menor; NT: casi amenazada; VU: vulnerable; EN: en peligro; CR: en peligro crítico.

Table 1. Number of species (percentage between parenthesis) included in the different IUCN categories for the 15 orders of Neotropical mammals. DD: Data Deficient, LC: Least Concern, NT: Near Threatened, VU: Vulnerable, EN: Endangered, CR: Crítically Endangered.

\begin{tabular}{lccccccc}
\hline Orden & DD & LC & NT & VU & EN & CR & Total \\
\hline Artiodactyla & $2(10.00)$ & $4(20.00)$ & $1(5.00)$ & $11(55.00)$ & $2(10.00)$ & $0(0.00)$ & 20 \\
Carnivora & $4(6.55)$ & $37(60.66)$ & $8(13.11)$ & $5(8.19)$ & $6(9.83)$ & $1(1.64)$ & 61 \\
Cetacea & $37(59.68)$ & $17(27.42)$ & $1(1.61)$ & $2(3.23)$ & $4(6.45)$ & $1(1.61)$ & 62 \\
Chiroptera & $33(10.78)$ & $216(70.59)$ & $22(7.19)$ & $24(7.84)$ & $8(2.61)$ & $3(0.98)$ & 306 \\
Cingulata & $5(23.81)$ & $8(38.10)$ & $5(23.81)$ & $3(14.29)$ & $0(0.00)$ & $0(0.00)$ & 21 \\
Didelphimorphia & $12(14.63)$ & $60(73.17)$ & $2(2.44)$ & $6(7.32)$ & $0(0.00)$ & $2(2.44)$ & 82 \\
Lagomorpha & $2(14.29)$ & $6(42.86)$ & $1(7.14)$ & $0(0.00)$ & $5(35.71)$ & $0(0.00)$ & 14 \\
Microbiotheria & $0(0.00)$ & $0(0.00)$ & $1(100)$ & $0(0.00)$ & $0(0.00)$ & $0(0.00)$ & 1 \\
Paucituberculata & $0(0.00)$ & $2(33.33)$ & $2(33.33)$ & $2(33.33)$ & $0(0.00)$ & $0(0.00)$ & 6 \\
Perissodactyla & $0(0.00)$ & $0(0.00)$ & $0(0.00)$ & $1(33.33)$ & $2(66.67)$ & $0(0.00)$ & 3 \\
Pilosa & $0(0.00)$ & $7(70.00)$ & $0(0.00)$ & $2(20.00)$ & $0(0.00)$ & $1(10.00)$ & 10 \\
Primates & $9(7.32)$ & $58(47.15)$ & $5(4.07)$ & $21(17.07)$ & $18(14.63)$ & $12(9.76)$ & 123 \\
Rodentia & $135(16.83)$ & $491(61.22)$ & $38(4.74)$ & $50(6.23)$ & $52(6.48)$ & $36(4.49)$ & 802 \\
Sirenia & $0(0.00)$ & $0(0.00)$ & $0(0.00)$ & $2(100)$ & $0(0.00)$ & $0(0.00)$ & 2 \\
Soricomorpha & $7(14.29)$ & $27(55.10)$ & $0(0.00)$ & $8(16.33)$ & $4(8.16)$ & $3(6.12)$ & 49 \\
& 246 & 935 & 86 & 137 & 101 & 59 & 1564 \\
\hline
\end{tabular}

(3 y 2, respectivamente) incluidas en alguna categoría de amenaza, mientras que los órdenes Microbiotheria y Didelphimorpha presentan los menores porcentajes $(<9.76 \%)$ de sus especies incluidas en dichas categorías. El resto de los órdenes presentan porcentajes variables, entre $11 \%$ (orden Cetacea) y $65 \%$ (orden Artiodactyla) de especies amenazadas (Figura 2).

La principal amenaza descrita en la literatura para los mamíferos terrestres es la destrucción del hábitat, producto de la implantación de sistemas agricolo-ganaderos, de la deforestación y la urbanización (Medan et al. 2011; Kelt and Meserve 2014; JiménezGarcía et al. 2014; Teta et al. 2014; Periago et al. 2015). Asimismo, se hace mención también al calentamiento global y los fenómenos que desencadena, a la caza, al tráfico ilegal y a la introducción de especies exóticas (Kelt and Meserve 2014; Teta et al. 2014; Periago et al. 2015). En el caso de los mamíferos marinos, su principal amenaza actual es la actividad pesquera, que creció de forma exponencial en los últimos 30 años. La mayoría de las poblaciones de estos mamíferos fueron severamente reducidas en los últimos siglos debido a la actividad pesquera y a la caza indiscriminada (Cabrera and Yepes 1940; Vaz-Ferreria 1982). Además, se menciona a la pesquería como uno de los mayores factores que afectan directamente a la recuperación de las mismas (Crespo et al. 1997; Dans et al. 2003a,b; Sepúlveda et al. 2007; Túnez and Pimper 2014). El impacto de las operaciones de pesca sobre los mamíferos marinos genera

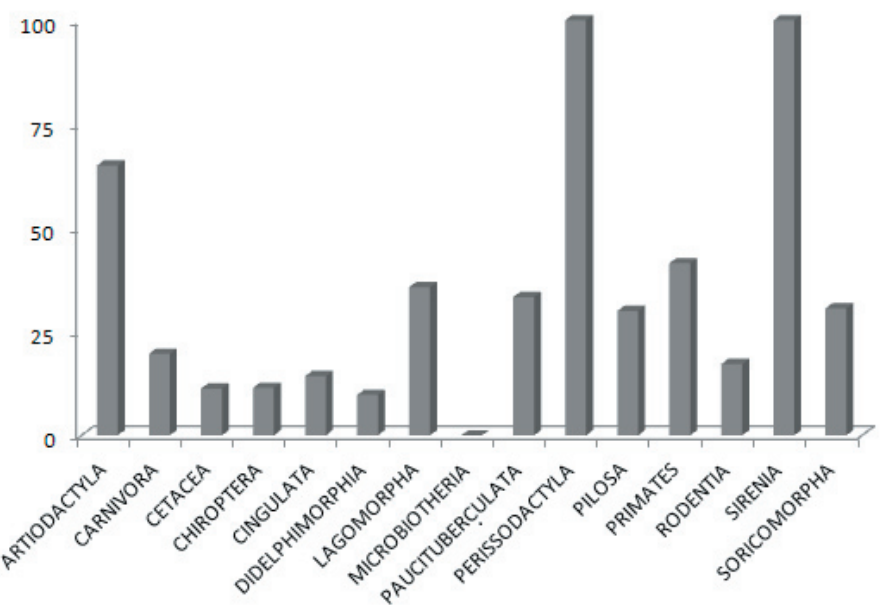

Figura 2. Porcentaje de especies amenazadas en cada uno de los 15 órdenes de mamíferos del Neotrópico.

Figure 2. Percentage of threatened species in each of the 15 orders of Neotropical mammals. 
una gran preocupación para la conservación de dichas especies. Debido a su rol de depredadores tope, los mamíferos marinos suelen morir enmallados incidentalmente en las redes de pesca $\mathrm{y}$, además, compiten por los recursos con las pesquerías (Northridge 1991; Crespo et al. 1997, 2000; Dans et al. 2003 a, b). La contaminación del agua, así como la pérdida de hábitat, también son consideradas amenazas importantes (Cappozzo and María 2013).

La disminución en la riqueza y en los tamaños poblacionales de los mamíferos neotropicales afecta a la estructura de los distintos ecosistemas en cuanto a la pérdida de heterogeneidad, la co-extinción de parásitos, la ruptura del equilibrio establecido con competidores y presas, y la disminución en las tasas de dispersión de semillas (Corlett 2013). Este último fenómeno fue revisado por Periago et al. (2015) para el Gran Chaco Sudamericano y por Dirzo y Miranda (1990) y Dirzo et al. (2007) para la selva mexicana. Dichos autores encontraron que los herbívoros medianos y grandes en esta región se encuentran en retracción numérica o amenazados; eso afecta a los procesos históricos de endozoocoria y la dinámica de la vegetación.

Como mencionamos antes, la mastofauna del Neotrópico está dominada por los roedores (Figura 1, Tabla 1). Este grupo contiene $~ 54 \%$ de las especies de mamíferos terrestres de esta región biogeográfica, con sólo $17.21 \%$ de sus especies amenazadas según los criterios seguidos por la UICN (Figura 2). Este orden contiene algunas especies (Calomys spp., Oligoryzomys spp., Zygodontomys spp., Sigmodon spp.) que presentan densidades poblacionales elevadas en sitios de hábitat natural fragmentado, muy antropizados o de cultivo extensivo (Utrera et al. 2000; Daily et al. 2003; Suzán et al. 2008; García et al. 2015). Si bien algunas especies generalistas se pueden adaptar a las técnicas de cultivo tradicionales, es evidente la disminución en la riqueza de roedores en los campos que utilizan grandes maquinarias y sistemas de riego (JiménezGarcía et al. 2014). Además, otros factores como el cambio climático y la persecución, al ser considerados como plagas, actúan de forma sinérgica con la fragmentación y la destrucción del hábitat (Kelt and Meserve 2014). En cuanto a la fragmentación del hábitat, algunas especies de roedores como Dasyprocta spp. y Myoprocta spp. se ven afectadas negativamente por este fenómeno (Asquith et al. 1997; Jorge 2008).

\section{Herramientas de la biología MOLECULAR EN EL ABORDAJE DE PROBLEMÁTICAS DE CONSERVACIÓN DE ESPECIES}

En las últimas décadas, la biología molecular ha desarrollado técnicas y metodologías de análisis genético que se convirtieron en herramientas muy útiles para una variedad grande de estudios en ecología, comportamiento y conservación (Frankham et al. 2002; Avise 2004; Rieseberg et al. 2011). Los marcadores moleculares basados en la amplificación por PCR de secuencias de ADN son muy útiles en el análisis de las relaciones entre individuos, grupos sociales, poblaciones o especies (Avise 2004). Algunos marcadores moleculares, como los microsatélites, funcionan como 'huellas dactilares' que permiten identificar individuos y sus relaciones de parentesco con otros miembros de la población. Cuando se combina esta información genética con resultados sobre comportamiento social y patrones de dispersión, se pueden describir la estructura social y la dinámica meta-poblacional, información clave para generar pautas de conservación de la fauna silvestre (Frankham et al. 2002). Por ejemplo, Túnez et al. (2009) utilizaron 16 marcadores microsatélite para analizar el éxito reproductivo de machos y hembras y las relaciones de parentesco entre los miembros de dos poblaciones nativas de coipo, Myocastor coypus, ubicadas en la Pampa Ondulada Bonaerense, Argentina. Los resultados obtenidos confirmaron estudios comportamentales previos (Guichón et al. 2003), que sugerían una varianza elevada en el éxito reproductivo. Se observó también que las hembras que componían los distintos grupos sociales en una de las poblaciones estaban más relacionadas genéticamente entre ellas que con las hembras de otros grupos, lo que sugería diferencias en la estructura social entre poblaciones, probablemente provocadas por diferentes características físicas del ambiente.

A nivel poblacional, determinar en qué forma una especie se encuentra dividida en unidades genéticamente distinguibles es fundamental para la conservación de la biodiversidad. Dado que los procesos evolutivos actúan a un nivel intraespecífico, las diferencias genéticas y los caracteres localmente adaptativos se acumularán en estas unidades a lo largo del tiempo. Este reservorio de diversidad genética y fenotípica 
incrementa la habilidad de las especies para sobrevivir a los cambios ambientales (Wang 2002). Así, uno de los principales objetivos de la genética de la conservación es preservar el potencial evolutivo de las especies y mantener la diversidad que se encuentra en las unidades genéticas. En consecuencia, el conocimiento de la estructura de estas unidades es necesario para el desarrollo de programas de conservación efectivos (Moritz 1994).

Dentro de una especie existen dos niveles de diferenciación genética denominadas Unidades de Manejo (UM) y Unidades Evolutivamente Significativas (UES). Una UM se define como cualquier población que intercambia muy pocos individuos con otras poblaciones y que, en consecuencia, es genéticamente distinta de éstas (Avise 2004). En la práctica, las UM se definen a partir de diferencias estadísticamente significativas en las frecuencias alélicas de marcadores moleculares neutrales. Los haplotipos del ADN mitocondrial son especialmente poderosos para identificar potenciales Unidades de Manejo (Moritz 1994; Avise 1995) debido a la relevancia especial de las líneas maternas en la demografía poblacional. Una UES es una población o un grupo de poblaciones de la misma especie con una historia evolutiva en el largo plazo que las distingue de otras poblaciones o unidades (Ryder 1986). Las UES son las fuentes principales de diversidad genética histórica y adaptativa dentro de una especie (Fraser and Bernatchez 2001), y como consecuencia de esto reciben una consideración especial en los esfuerzos de conservación (Moritz 1994; Bernatchez 1995; Avise 2000). Existen varios requisitos para la definición de una UES. Desde el punto de vista genético, las UES son identificadas como grupos de poblaciones recíprocamente monofiléticas para alelos del ADN mitocondrial y que también difieren significativamente en la frecuencia de alelos de loci nucleares (Moritz 1994). Otros requisitos son las diferencias en rasgos fenotípicos, como medidas craneanas y peso corporal, así como en el comportamiento e historia de vida (Moritz 1994; Frankham et al. 2002; Wang 2002). Tanto los marcadores mitocondriales como nucleares han sido utilizados con éxito en la determinación de unidades genéticas. Por ejemplo, Napolitano et al. (2014) utilizaron una región el ADNmt y marcadores microsatélites para estudiar la filogeografía y las barreras al flujo génico en el área de distribución del gato güiña (Leopardus guigna). Los análisis indicaron la presencia de al menos dos UM; cada una correspondía a las dos subespecies antes descriptas. Al tener cada una de estas UM diferentes historias biogeográficas, patrones de variabilidad genética y amenazas reales, los autores realizaron distintas sugerencias de manejo para cada una de estas unidades descriptas.

El abordaje desde la genética de la conservación de problemas relacionados con los efectos de la fragmentación del hábitat sobre la supervivencia de poblaciones de fauna silvestre también ha sido muy significativo. Cuando la actividad antrópica provoca el aislamiento de las poblaciones en parches de ambiente apto separados por una matriz amplia de hábitat muy alterado, el uso de marcadores moleculares permite evaluar el grado de aislamiento genético de las poblaciones locales y su riesgo de extinción. En este sentido, Rippenger et al. (2013) realizaron un estudio en una población de murciélagos de la especie Dermanura watsoni, que habita un bosque al noreste de Costa Rica, fragmentado por la actividad agrícola. Dentro del grupo de los mamíferos, por su alta capacidad de dispersión, los murciélagos son considerados como especies con una alta resistencia a la pérdida de variabilidad genética debido a la fragmentación del hábitat. Sin embargo, estos autores, utilizando como marcador molecular a la secuencia nucleotídica de la región control del ADN mitocondrial, encontraron una alta estructuración genética entre parches de ambiente apto, que no podría ser explicada por la distancia geográfica que separa dichos parches.

Por otro lado, los marcadores moleculares también permiten evaluar si existe direccionalidad en el flujo génico, es decir, si se establecen relaciones de tipo fuentesumidero dentro de meta-poblaciones, en las que una población estable provee de individuos y genes a poblaciones en parches de ambiente subóptimo (Runge et al. 2006 ). Por ejemplo, Campos-Krauer y Wisely (2011) usaron un modelo de nicho ecológico para modelar la distribución actual del carpincho, H. hydrochaeris, en el Gran Chaco paraguayo, y la compararon luego con la distribución de esa especie 80 años atrás. Los resultados de su modelación mostraron que la especie extendió su distribución luego de que algunas zonas del Gran Chaco, que en el pasado eran zonas forestales, fueron transformadas en zonas de pastizales inundables tras su deforestación. Posteriormente, utilizando un fragmento de 386 pb correspondiente a la región control 
del ADN mitocondrial, confirmaron dicho escenario de expansión poblacional, e identificaron que las poblaciones de carpincho ubicadas en el Río Pilcomayo, el sur del Bajo Chaco y el Río Paraguay habrían actuado como poblaciones fuente de individuos que colonizaron las nuevas zonas deforestadas del Gran Chaco.

Algunos planes de conservación de especies incluyen la cría en cautiverio y la reintroducción de individuos en las poblaciones naturales. En estos casos, el uso de marcadores moleculares es muy útil para monitorear genéticamente a las población en cautiverio y para asegurar que conserven una variabilidad genética elevada; así se evita la depresión por endogamia (Ruiz-García et al. 2007; Crespín 2011; Oliveira et al. 2011). Asimismo, la reintroducción debe tener lugar en una población genéticamente relacionada para evitar la depresión por exogamia (Soorae 2008; Ruiz-García et al. 2010), por lo que el uso de marcadores moleculares es necesario también al momento de seleccionar la o las poblaciones donde se reintroducirán los individuos.

Como mencionamos en el párrafo anterior, la conservación "ex situ" es una estrategia utilizada para mantener "stocks" de individuos en cautiverio, fuera de su hábitat natural, que suele encontrarse modificado y presentando condiciones adversas para la especie en cuestión. El objetivo de la conservación ex situ es establecer poblaciones autosostenibles minimizando la endogamia, la pérdida de variabilidad genética y la adaptación al cautiverio (Frankham 2008). Estos son algunos de los tantos factores que condicionan una reintroducción exitosa. En este sentido, se hace necesario estimar la variabilidad genética, los índices de endogamia, la ocurrencia de cuellos de botella genéticos y la posibilidad de cruces entre distintos taxones moleculares en estas poblaciones en cautiverio. En línea con estos objetivos, Ruiz-García et al. (2007) llevaron adelante un estudio en 14 especies de primates platirrinos (Cebus albifrons, Cebus apella, Cebus capucinus, Aotus nancymae, Saguinus oedipus, Saguinus leocopus, Saguinus geoffroyi, Saimiri sciureus, Saimiri boliviensis, Alouatta seniculus, Lagothrix lagotricha, Ateles fusciceps, Ateles hybridus y Ateles belzebuth) que conforman poblaciones artificiales en zoológicos colombianos y en un centro peruano de reproducción en cautiverio. Por medio de 10 loci microsatélites pudieron determinar las variabilidades genéticas, la presencia de posibles híbridos y el pasaje por recientes cuellos de botella, así como también se pudieron elaborar algunas recomendaciones para el correcto mantenimiento de estos stocks.

El tráfico ilegal y el comercio de especies es uno de los grandes problemas para la conservación de algunas especies, sobre todo las más carismáticas. Para los primates esto constituye un problema constante. Año a año, cientos de ejemplares son decomisados y puestos al cuidado de distintas organizaciones de carácter público y privado. Ruiz-García et al. (2010) llevaron adelante un estudio genético con distintos ejemplares de los géneros Saguinus, Aotus y Cebus decomisados en Colombia, en pos de identificar posibles zonas de procedencia y generar reintroducciones exitosas. Mediante la secuenciación del gen mitocondrial de la Citocromo Oxidasa II a partir del ADN obtenido de cada individuo decomisado, y utilizando una filogenia de la especie realizada con secuencias obtenidas de individuos de diferentes poblaciones silvestres conocidas, se pudo determinar las áreas geográficas de procedencia de los individuos decomisados y liberar a cada uno de ellos en el área correspondiente.

Además, las técnicas de biología molecular han permitido el avance en la identificación de delitos concernientes a la conservación de la biodiversidad. El análisis de ADN forense permitió identificar la caza furtiva, el comercio ilegal y el contrabando ilegal de especies amenazadas, entre otros delitos (Iyengar 2014). En lo que respecta a mamíferos neotropicales, se usan distintos marcadores moleculares para identificar carne de guanaco (Lama glama), venado de las pampas (Ozotoceros bezoarticus) y carpincho (H. hydrochaeris) producto de la caza furtiva (Marín et al. 2009; Sanches et al. 2012).

Es importante destacar el desarrollo en los últimos 20 años de distintas técnicas de muestreo genético no invasivo que permiten la obtención de ADN sin la necesidad de capturar o manipular a los individuos. Estas técnicas usan signos que los animales dejan en su hábitat producto de su presencia y actividad (Goossens and Bruford 2009). Mediante estas técnicas, pelos, plumas, heces, orina, cáscaras de huevo, escamas, tejido blando y duro de animales muertos, especímenes de museo y hasta fósiles son potenciales fuentes de ADN (Beja-Pereira et al. 2009). Se sabe que obtener datos genéticos a partir de muestreos no 
invasivos puede ser costosa y laboriosa, pero la facilidad del muestreo (comparado con los métodos convencionales), la disminución del estrés en los animales de estudio y la eficiencia en la obtención de los datos validan estas técnicas como una alternativa aceptable para realizar estudios genéticos, en particular cuando se trabaja con especies elusivas o amenazadas (Taberlet et al. 1999; Waits and Paetkau 2005; Nardelli et al. 2011). Por estas características, estos métodos de muestreo resultan muy útiles al llevar adelante estudios en el área de la genética de la conservación.

Lastécnicasnoinvasivas demuestreogenético se utilizan para realizar diversos estudios en distintas especies de mamíferos neotropicales (González and Barbanti Duarte 2007; RuizGarcía et al. 2007; Trinca et al. 2013; Rodgers and Janečka 2013; Grattarola et al. 2015; Byrne et al. 2015; Trigila et al. 2016). Particularmente, para los mamíferos se han realizado distintos esfuerzos por optimizar la obtención de ADN a partir de pelos y heces. Siguiendo esta línea, se pusieron a punto trampas de pelo para distintas especies (Castro-Arellano et al. 2008; Biondo et al. 2010; García-Alaniz et al. 2010) y se propusieron protocolos para aumentar la eficiencia de las extracciones de $\operatorname{ADN}$ a partir de heces mediante la remoción de los inhibidores que éstas contienen (Hebert et al. 2011; Nardelli et al. 2011; Panasci et al. 2011; Maturrano et al. 2012). Por otro lado, Gomes Rocha et al. (2015) lograron recientemente recuperar $\mathrm{ADN}$ de pequeños mamíferos a partir de huesos presentes en egagrópilas de la lechuza común, Tyto alba.

Entre las aplicaciones del muestreo no invasivo en genética de la conservación, los censos y la determinación del tamaño poblacional efectivo $\left(\mathrm{N}_{\mathrm{e}}\right)$ constituyen estudios fundamentales en la caracterización de las poblaciones naturales, con un impacto muy bajo sobre ellas. En este sentido, los marcadores microsatélites se usan para asignar las muestras a individuos y para estimar con un alto grado de confiabilidad el tamaño poblacional a partir de la fórmula de captura-recaptura (Petit and Valiere 2006). Asimismo, estos marcadores moleculares son útiles para determinar el $\mathrm{N}_{\mathrm{e}}$ mediante distintos algoritmos (Luikart et al. 2010).

Por último, se debe mencionar el trabajo de Rodgers y Janečka (2013), quienes llevaron adelante una revisión que detalla aquellos estudios en los que se empleó ADN obtenido por muestreo no invasivo con el objetivo de realizar estudios genéticos en diferentes especies de félidos. El $60 \%$ de esos trabajos $(n=12)$ tuvieron como especie o especies de estudio a félidos neotropicales. La mayoría de estos trabajos realizaron distintos aportes a la conservación de esas especies, lo que denota los esfuerzos científicos en pos de la conservación de esta familia de carnívoros del Neotrópico.

\section{ESFUERZOS DESIGUALES}

Como mencionamos antes, en la última década se desarrollaron tres índices ad hoc para cuantificar los esfuerzos científicos en el campo de la genética de la conservación. Los resultados del cálculo de estos índices para cada uno de los 15 órdenes analizados se muestran en la Tabla 2 y la Figura 3. El análisis del índice PPE muestra la existencia de esfuerzos desiguales en el estudio de las especies pertenecientes a los distintos órdenes, y se observa una prevalencia de estudios en Perissodactyla y Sirenia ( $\mathrm{PPE}=2.67$ y 5.00, respectivamente) (Tabla 2, Figura 3A), mientras que en 7 órdenes se observó un $P P E \leq 0.1$, lo que representa menos de un artículo publicado cada 10 especies en cada uno de estos órdenes. Entre estos órdenes se destaca Paucituberculata, para el cual no existen trabajos publicados en la temática para ninguna de las 6 especies que lo componen.

Tabla 2. Valores de los índices utilizados para evaluar el esfuerzo en el área de la genética de la conservación en el estudio de los mamíferos neotropicales. PPE: índice de publicaciones por especie; PEA: índice de publicaciones en especies amenazadas; IDI: índice de interés.

Table 2. Values of the indices used to evaluate the conservation genetics efforts in the study of neotropical mammals. PPE: Index of publications by species, PEA: Index of publications in threatened species, IDI: Index of interest.

\begin{tabular}{llll}
\hline Orden & PPE & PEA & IDI \\
\hline Artiodactyla & 0.55 & 0.54 & 0.98 \\
Carnivora & 0.59 & 0.75 & 1.27 \\
Cetacea & 0.44 & 0.86 & 1.97 \\
Chiroptera & 0.03 & 0.06 & 1.94 \\
Cingulata & 0.10 & 0.33 & 3.50 \\
Didelphimorphia & 0.09 & 0.00 & 0.00 \\
Lagomorpha & 0.07 & 0.20 & 2.8 \\
Microbiotheria & 1.00 & - & - \\
Paucituberculata & 0.00 & 0.00 & - \\
Perissodactyla & 2.67 & 2.67 & 1.00 \\
Pilosa & 0.60 & 1.00 & 1.67 \\
Primates & 0.33 & 0.45 & 1.35 \\
Rodentia & 0.03 & 0.06 & 2.21 \\
Sirenia & 5.00 & 5.00 & 1.00 \\
Soricomorpha & 0.00 & 0.00 & - \\
\hline
\end{tabular}



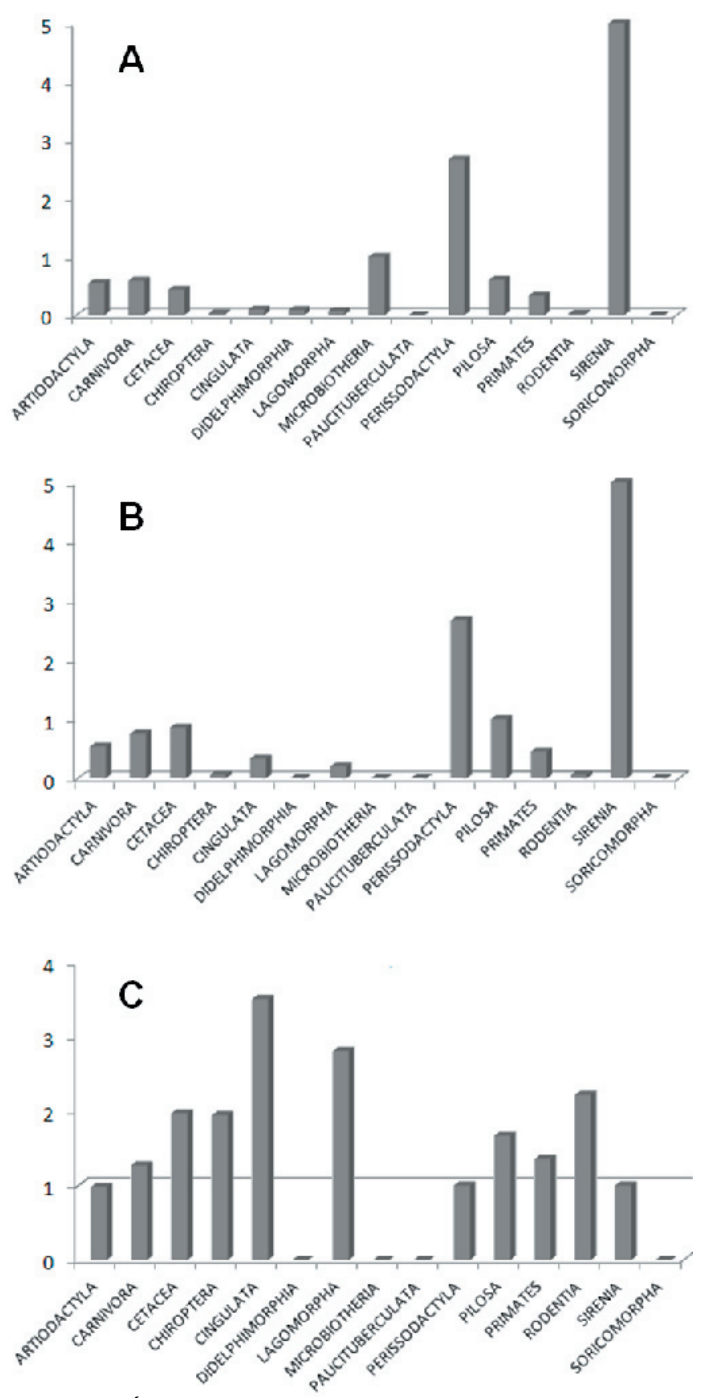

Figura 3. Índices ad hoc utilizados para cuantificar la producción científica en el área de la genética de la conservación de mamíferos neotropicales en la última década. A) Índice PPE (publicaciones por especie); B) Índice PEA (publicaciones sobre especies amenazadas); C) Índice IDI (índice de interés).

Figure 3. Ad hoc indices used to quantify scientific production in the conservation genetics area of Neotropical mammals in the last decade. A) PPE Index (publications by species), B) PEA Index (publications on threatened species), C) IDI Index (Index of interest).

Si bien los órdenes más estudiados según este índice presentan sólo dos (Sirenia) y tres (Perissodactyla) especies, y entre los menos estudiados se encuentran los más diversos (como Rodentia y Chiroptera), los valores obtenidos marcan grandes diferencias en la cantidad de estudios realizados en cada uno de los órdenes en función del número de especies que los componen. La existencia de estas diferencias se refuerza al prestar atención a cuáles son las especies de estudio dentro de cada uno de ellos. En el orden Carnivora, por ejemplo, hemos observado que los esfuerzos en investigación se centraron mayoritariamente en especies de las familias Felinae, Otariinae y Mustelinae (83\% de los estudios en el orden), posiblemente las que contienen a las especies más carismáticas en dicho grupo taxonómico. En cuanto a los resultados obtenidos para el índice PEA, el patrón observado es similar a lo obtenido con el índice PPE (Tabla 2, Figura 3B). Los órdenes Perissodactyla y Sirenia presentaron los valores más altos de PEA (2.67 y 5.00, respectivamente) (Tabla 2, Figura 3B), los que coinciden con los valores de PPE, ya que todas las especies de los dos órdenes se encuentran amenazadas. Por el contrario, los órdenes Didelphimorphia, Paucituberculata y Soricomorpha, que presentan 8,2 y 15 especies amenazadas, respectivamente, presentaron valores de $\mathrm{PEA}=0$, ya que no existen trabajos publicados en estas especies. Para el orden Microbiotheria, que no posee especies amenazadas, este índice no se pudo calcular. El resto de los órdenes presentaron valores de PEA entre 0.06 (para Chiroptera y Rodentia) y 1 (para Pilosa); en los órdenes Carnivora y Cetacea se observaron valores cercanos a 1 . Nuevamente, los valores que se obtuvieron marcan diferencias grandes en la cantidad de estudios realizados en cada uno de los órdenes en función del número de especies, en este caso amenazadas, que los componen. Finalmente, cuando se analizaron los resultados obtenidos mediante el IDI, se observó que tanto Perissodactyla como Sirenia presentan un IDI $=1$, ya que todas las especies que componen estos órdenes se encuentran amenazadas (Tablas 1 y 2, Figura 3C). Lo contrario ocurre en el orden Microbiotheria, en el que el IDI no se pudo calcular ya que la única especie en el orden no está amenazada. Por último, 8 de los 12 órdenes restantes presentan un IDI mayor a 1 (Tabla 2, Figura 3C), lo que evidencia que dentro de estos grupos son más estudiadas las especies que se encuentran amenazadas. Este fenómeno fue más marcado en los órdenes Cetacea, Chiroptera, Cingulata, Lagomorpha y Rodentia, que mostraron valores cercanos o mayores a 2.

Si bien son muchas las variables que definen qué especies son utilizadas como objeto de estudio, entendemos que en estas decisiones estarían primando aspectos de tipo económico por sobre otros aspectos también importantes como los biológicos y ambientales. En este sentido, observamos que las especies o grupos más estudiados son aquellos que presentan un interés económico 
mayor, ya sea por ser especies carismáticas, emblemáticas de alguna región turística, o fuente de recursos explotables como cuero, piel, lana o carne. De todos modos, debemos reconocer que, en ocasiones, la abundancia de la especie o la dificultad de encontrar restos de las mismas condicionan la posibilidad de realizar estudios con ella.

\section{Críticas al Concepto de Unidad DE MANEJO Y LA IMPORTANCIA DE DETERMINAR LA CONECTIVIDAD}

El desarrollo sustentable, dado a conocer por el Informe Brundtland en 1987, promueve el uso de los recursos naturales para satisfacer las necesidades económicas, sociales, de diversidad cultural y de ambiente sano de la generación actual, sin comprometer a las futuras (Bruni 2000). De este modo, integra las problemáticas socioeconómicas al cuidado del ambiente. De esta manera, la relación con el ambiente se subordina al desarrollo económico. En palabras de Sauvé (1999) "la cuestión ética es no exceder la capacidad de carga del ambiente [capacidad de ser alterado], mientras satisfaga las necesidades (lo que no se ha discutido) actuales y futuras de las sociedades de estilo occidental".

De modo similar, el concepto de Unidad de Manejo resulta confuso dado que ya se usaba en la década de 1980 para denominar a los stocks de pesca (Ryman and Utter 1987). El empleo de un término derivado de una actividad extractivista cuando se desea hacer referencia a una población a conservar es, si se quiere, contradictorio. Asimismo, el concepto de Manejo de Fauna hace referencia a un uso de la vida silvestre con el fin de cumplir con "objetivos humanos" (Ojasti and Dallmeier 2000). En dichos objetivos suelen primar los aspectos vinculados al desarrollo económico y queda en segundo lugar, otra vez, el cuidado del ambiente.

Conceptos como UM o MF se usan en numerosas ocasiones con fines conservacionistas y como fundamento para la educación ambiental (Sauvé 1999; Villaverde 2009). Sin desmerecer los esfuerzos que se realizan bajo esta lógica en pos de mantener las poblaciones silvestres, en muchos casos no se reflexiona profundamente en torno al uso del ambiente y se pone más énfasis en el aislamiento de las poblaciones que en la conectividad. Además, estos enfoques brindan herramientas que legitiman la alteración o destrucción del hábitat.
Muchas especies amenazadas habitan zonas donde el ambiente se encuentra fragmentado. En la última década, un gran número de trabajos científicos usaron herramientas genéticas para determinar cómo la fragmentación del hábitat determina la estructura genética de las poblaciones, definiendo así diferentes UM. Sin embargo, muy pocos estudios genéticos se centran en identificar corredores biológicos que permitan mantener el flujo génico entre las diferentes poblaciones y, en consecuencia, la diversidad genética de las especies silvestres. Un ejemplo de ellos es el trabajo de De Angelo et al. (2013), quienes emplearon un modelado de distribución del jaguar (Panthera onca) en una región de la selva paranaense y determinaron el efecto de la antropización y de otros factores ambientales sobre la presencia de este felino. Para identificar la presencia de jaguares se valieron de la observación de huellas, de radio telemetría, de trampas cámara y de la amplificación y secuenciación de una región del ADNmit a partir de muestras de heces. De esta manera determinaron la importancia de los corredores para la presencia de esta especie. Asimismo, teniendo en cuenta variables ambientales que correlacionaron de forma positiva con la actividad de los jaguares en la zona, redefinieron las zonas geográficas que se deben tener en cuenta como corredores biológicos, y delinearon, además, algunas recomendaciones para efectivizar la conectividad y reducir la mortandad de jaguares.

La creación de corredores entre fragmentos de hábitat (o la conservación de los existentes), frecuentemente recomendada por razones no-genéticas, puede restablecer (o mantener) el flujo génico entre poblaciones aisladas. Sin embargo, las especies varían en sus requerimientos para que un corredor actúe realmente como una ruta de migración efectiva. Lindenmayer y Nix (1993) muestran una serie de resultados clave para el diseño de corredores de fauna silvestre. Las estimaciones de la aptitud del hábitat, del radio de acción de las especies blanco y las predicciones asociadas acerca del ancho mínimo de los corredores parecen ser insuficientes. La efectividad de los corredores de fauna silvestre se puede mejorar si se consideran criterios adicionales de diseño, incluyendo el contexto geográfico del sitio y su conectividad y la estructura social, la dieta y los patrones de forrajeo de las especies blanco. De esta manera, los principios generales del diseño de corredores necesitan incluir un rango amplio 
de criterios de diseño. Se requiere entender estos principios a fin de desarrollar estrategias adecuadas para conservar la biodiversidad en paisajes fragmentados o degradados. El uso de marcadores moleculares resulta clave ya que puede aportar información valiosa acerca de la estructura social en las distintas especies, la conectividad entre parches y la direccionalidad en el flujo génico.

\section{Perspectivas a futuro $Y$ LIMITACIONES}

A pesar de la utilidad demostrada de los marcadores moleculares en el estudio de la ecología, comportamiento y conservación de diferentes especies de mamíferos (Rieseberg et al. 2011), el uso de estas herramientas genéticas presenta también limitaciones. Väli et al. (2008) y Ljungqvist et al. (2010) compararon la variabilidad resultante de un conjunto de loci microsatélites con la obtenida mediante marcadores SNP (polimorfismo de nucleótido simple) correspondientes a las secuencias nucleotídicas de diferentes intrones y regiones de ADN no codificantes. En el primero de estos estudios, en el que se utilizaron datos genéticos obtenidos de ocho poblaciones de mamíferos de distintas partes del planeta, los autores demostraron que los microsatélites, uno de los marcadores moleculares más polimórficos de los conocidos en la actualidad, pueden subestimar la variabilidad genética de las poblaciones naturales. Por el contrario, en el segundo de estos estudios, los autores demostraron por medio de simulaciones que los marcadores moleculares microsatélites podrían predecir mejor la variabilidad genómica. A pesar de estos resultados contradictorios, ambos estudios reconocen la potencia de las secuencias repetitivas en el análisis de la variabilidad en una escala temporal corta, y recomiendan el uso conjunto de marcadores microsatélites y de la secuenciación de regiones de ADN, dados los enormes avances que se han dado durante la última década en materia de secuenciación de genomas y análisis bioinformático.

Las nuevas tecnologías de secuenciación masiva (NGS, Next Generation Sequencing o Secuenciación de Segunda Generación) permiten la obtención rápida de secuencias nucleotídicas de partes de genomas y hasta genomas completos (Escalante et al. 2014). Con la secuenciación masiva se pueden detectar decenas de miles de marcadores moleculares microsatélites y SNP para diferentes especies (Ekblom and Galindo 2011; Escalante et al. 2014). Si bien estas técnicas presentan un costo bajo para los científicos de países desarrollados, su uso cotidiano todavía resulta poco accesible para la mayoría de los presupuestos de los grupos de investigación latinoamericanos.

Es sabido que en poblaciones pequeñas, la depresión por endogamia y el efecto de la deriva genética llevan a la pérdida de alelos que podrían ser benéficos en ese contexto. De este modo, al realizar estudios moleculares empleando regiones de ADN no codificantes, ¿sería lógico pensar en correlacionar la variabilidad genética hallada con el "fitness" de la población? (Taft 2012). En este sentido, parece más interesante evaluar las bases genéticas de la adaptación a la hora de seleccionar marcadores moleculares para estudios orientados a la conservación. Las técnicas de secuenciación masiva brindan la posibilidad de obtener secuencias de múltiples sitios de ADN codificante en paralelo, así como también el estudio a nivel transcriptómico. Esta última aplicación permite caracterizar individuos según su perfil transcriptómico, evaluar los niveles de expresión de distintos genes y detectar genes candidatos, todo ello apuntado a desentrañar los fenómenos de adaptación a nivel molecular y analizar el estado de conservación de una población (Ekblom and Galindo 2011).

Teniendo en cuenta el amplio abanico de herramientas que presentan las técnicas de secuenciación masiva en el área de la genética de la conservación, es recomendable el uso de más de un marcador molecular para realizar estimaciones poblacionales. Además, sería muy valioso considerar aquellos loci que tengan un posible valor adaptativo para la población, tales como el complejo mayor de histocompatibilidad (CMH), genes implicados en la resistencia o tolerancia a contaminantes o cualquier otro determinante genético que pueda contrarrestar los efectos de estresores ambientales significativos en el ambiente. De este modo, los datos obtenidos, en conjunto con valores de fitness y otras variables ambientales se podrían usar para realizar análisis de viabilidad poblacional (AVP), tal como lo describen Pierson et al. (2015). En este sentido, el empleo de marcadores moleculares neutrales, como microsatélites, región control del ADN mitocondrial, entre otros, no poseen a priori ninguna influencia en la posibilidad de adaptación al medio. Por lo tanto, una baja variabilidad neutra podría no ser un buen indicador de peligro de extinción. Sin 
embargo, debemos considerar la posibilidad de que algunos marcadores neutros estén ligados a genes que no lo son. El uso de un número significativo de estos marcadores, distribuidos a lo largo del genoma, podría ser una buena indicación de riesgo.

Si se tienen en cuenta los costos y las limitaciones de las técnicas moleculares aplicadas al estudio de especies silvestres, entendemos que se establece un compromiso entre la calidad de los datos a obtener y el dinero disponible por los equipos de investigación que pretenden incluir marcadores moleculares en sus estudios en conservación. Aquellos equipos que cuenten con fondos suficientes podrán recurrir a las técnicas NGS y encarar proyectos a largo plazo, de modo de procesar la gran cantidad de información obtenida. Así podrán indagar con mayor profundidad los procesos adaptativos que se estén llevando adelante en la región de estudio y, además, integrar variables ecológicas, demográficas, filogenéticas, evolutivas o sociales para llevar a cabo AVPs. Por otro lado, aquellos equipos de trabajo que no posean presupuestos holgados deberán optar por el uso de algunos marcadores moleculares. En estos casos sería importante poder emplear marcadores neutrales y selectivos en el marco del mismo proyecto. De este modo, los primeros pueden dar cuenta de procesos demográficos a corto y largo plazo, mientras que los segundos pueden dar una idea acerca de los procesos selectivos que estarían ocurriendo en una población. Vale destacar que la elección de la especie en estudio también es una limitante en el caso de grupos de investigación que no pueden encarar una secuenciación completa o masiva ya que la/s especie/s de estudio deberán contar con datos moleculares previos o estar emparentadas a una que sí cuente con los mismos.

\section{Cierre}

La genética de la conservación ha proporcionado numerosas herramientas para comprender el impacto de distintos fenómenos naturales o antropogénicos en la dinámica poblacional y en los procesos microevolutivos asociados. Debemos resaltar, además, la particularidad de las técnicas de muestreo no invasivas y su amplio desarrollo en los últimos años. Este conjunto de técnicas disminuye considerablemente el impacto de la labor científica sobre el grupo en estudio, aprovechando materiales biológicos que evidencian la presencia de los animales. Esto es de suma importancia para el estudio de especies evasivas, que presentan tamaños poblacionales pequeños o se encuentran amenazadas, como es el caso de algunas especies de félidos y mustélidos.

Si bien la genética de la conservación generó aportes valiosos al estudio de los mamíferos neotropicales, entendemos que los esfuerzos realizados se han "dosificado" de manera desigual entre los distintos grupos taxonómicos. A partir de esta revisión detectamos que estos esfuerzos desiguales no se deben necesariamente al estado de conservación de los grupos de mamíferos en cuestión.

La fragmentación del conocimiento en disciplinas permite la especialización y el análisis minucioso en las distintas áreas del conocimiento que se han desarrollado. Sin embargo, esta fragmentación obstaculiza el abordaje integral delas distintas problemáticas, así como un análisis crítico del fenómeno que dé cuenta de las múltiples variables asociadas. En este sentido, entendemos que los esfuerzos por la conservación de la biodiversidad en general, y de la genética de la conservación en particular, requieren de abordajes interdisciplinarios con una mirada holística que atienda cada problema en particular. Es decir, los estudios en el área de la genética de la conservación deberían ser parte de trabajos más integrales que incluyan la dimensión fisiológica, ecológica y etológica de la especie en estudio y su entorno, e idealmente, las dimensiones sociológicas, económicas y antropológicas del problema en cuestión. Así, la transferencia de información a entes con capacidad de decisión o el trabajo en conjunto con los mismos sería una tarea más sencilla y eficiente. El empleo de técnicas NGS y de AVPs van en ese sentido y posibilitan la obtención de resultados más integrales.

Agradecimientos. Al Departamento de Ciencias Básicas de la Universidad Nacional de Luján y al Consejo Nacional de Investigaciones Científicas y Técnicas (CONICET). 


\section{REFERENCIAS}

Antonelli, A., and I. Sanmartín. 2011. Why are there so many plant species in the Neotropics? Taxon 60 (2):403-414.

Asquith, N. M., S. J. Wright, and M. J. Clauss. 1997. Does mammal community composition control recruitment in neotropical forests? Evidence from Panama. Ecology 78:941-6.

Avise, J. C. 1995. Mitochondrial DNA polymorphism and a connection between genetics and demography of relevance to conservation. Conserv Biol 9:686-90.

Avise, J. C. 2000. Phylogeography: the history and formation of species. Harvard University Press, Cambridge, Massachusetts, Estados Unidos.

Avise, J. C. 2004. Molecular markers, natural history, and evolution. Sinauer Associates Inc., Sunderland, Massachusetts, Estados Unidos.

Barletta, M., A. J. Jaureguizar, C. Baigun, N. F. Fontoura, A. A. Agostinho, V. M. F. Almeida-Val, A. L. Val, R. A. Torres, L. F. Jimenes-Segura, T. Giarrizzo, N. N. Fabré, V. S. Batista, C. Lasso, D. C. Taphorn, M. F. Costa, P. T. Chaves, J. P. Vieira, and M. F. M. Correa. 2010. Fish and aquatic habitat conservation in South America: a continental overview with emphasis on neotropical systems. J Fish Biol 76:2118-76.

Beja-Pereira, A., R. Oliveira, P. C. Alves, M. K. Schwartz, and G. Luikart. 2009. Advancing ecological understandings through technological transformations in noninvasive genetics. Mol Ecol Resour 9:1279-301.

Bernatchez, L., and A. Osinov. 1995. Genetic diversity of trout (genus Salmo) from its most eastern native range based on mitochondrial DNA and nuclear gene variation. Mol Ecol 4:285-98.

Bertorelle, G., M. W. Bruford, H. C. Hauffe, A. Rizzoli, and C. Vernesi. 2009. Population genetics for animal conservation. Cambridge university press, Cambridge, Massachusetts, Estados Unidos.

Biondo, C., H. S. Goncalves, C. Bernardo, and M. Galetti. 2010. Hair trap efficacy to sample white-lipped peccaries (Tayassu pecari). Suiform Soundings 24-7.

Bruni, L. 2000. Humanizar la Economía. Editorial Ciudad Nueva. Ciudad Autónoma de Buenos Aires, Argentina.

Byrne, M. S., R. D. Quintana, M. L. Bolkovic, M. H. Cassini, and J. I. Túnez. 2015. The role of river drainages in shaping the genetic structure of capybara populations. Genetica 143:645-56.

Cabrera, A., J. Yepes. 1940. Los otáridos. Mamíferos sudamericanos. Historia Natural Ediar. Pp. 177-180.

Campos-Krauer, J. M., and S. M. Wisely. 2011. Deforestation and cattle ranching drive rapid range expansion of capybara in the Gran Chaco ecosystem. Glob Change Biol 17:206-18.

Castro-Arellano, I., C. Madrid-Luna, T. E. Lacher, and L. León-Paniagua. 2008. Hair-trap efficacy for detecting mammalian carnivores in the Tropics. J Wildlife Manage 72:1405-12.

Capozzo, L. H., M. V. Panebianco, and J. I. Túnez. 2013. Marine Mammals in a Changing World. Pp. 219-259 en A. H. Arias and M. C. Menéndez (eds.). Marine Ecology in a Changing World. CRC Press, Boca Ratón, Florida, Estados Unidos.

Ceballos, G., P. R. Ehrlich, A. D. Barnosky, A. García, R. M. Pringle, and T. M. Palmer. 2015. Accelerated modern human-induced species losses: Entering the sixth mass extinction. Science Advances 1:e1400253.

Corlett, R. T. 2013. The shifted baseline: Prehistoric defaunation in the tropics and its consequences for biodiversity conservation. Biol Conserv 163:13-21.

Costa, L. P., Y. L. R. Leite, S. L. Mendes, and A. D. Ditchfield. 2005. Mammal conservation in Brazil. Conserv Biol 19: 672-9.

Courchamp, F., B. D. Hoffmann, J. C. Russell, C. Leclerc, and C. Bellard. 2014. Climate change, sea-level rise, and conservation: keeping island biodiversity afloat. Trends Ecol Evol 29:127-30.

Crespín, S. J. 2011. Sobre la conservación de Ateles geoffroyi (Primates, Atelidae) en El Salvador: Consideraciones genéticas para la formación de poblaciones en cautiverio. Revista Latinoamericana de Conservación 2:30-7.

Crespo, E. A., M. K. Alonso, S. L. Dans, N. A. García, S. N. Pedraza, M. Coscarella, and R. González. 2000. Incidental catches of dolphins in mid-water trawls for Argentine anchovy (Engraulis anchoita) off the Argentine shelf. Journal of Cetacean Research and Management 2:11-6.

Crespo, E. A., S. N. Pedraza, S. L. Dans, M. K. Alonso, L. M. Reyes, N. A. García, M. Coscarella, and A. C. Schiavini. 1997. Direct and indirect effects of the highseas fisheries on the marine mammal populations in the northern and central Patagonian coast. J. Northwest Atl Fish Sci 22:189-207.

Daily, G. C., G. Ceballos, J. Pacheco, G. Suzán, and A. Sánchez-Azofeifa. 2003. Countryside biogeography of neotropical mammals: conservation opportunities in agricultural landscapes of Costa Rica. Conserv Biol 17:1814-26.

Dans, S. L., E. A. Crespo, S. N. Pedraza, and N. García. 2003. Interactions between marine mammals and high seas fisheries in Patagonia under an integrated approach. Pp. 100-115 en N. Gales, M. Hindell and R. Kirkwood (eds.). Marine mammals: Fisheries, Tourism and Management Issues. CSIRO Publishing, Collingwood, Australia.

Dans, S. L., M. Koen-Alonso, S. N. Pedraza, and E. A. Crespo. 2003. Incidental catch of dolphins in trawling fisheries off Patagonia, Argentina: can populations persist? Ecol Appl 13:754-62.

De Angelo, C., A. Paviolo, T. Wiegand, R. Kanagaraj, and M. S. Di Bitetti. 2013. Understanding species persistence for defining conservation actions: a management landscape for jaguars in the Atlantic Forest. Biol conserv 159:422-33.

de Oliveira, L. R., M. C. Gehara, L. D. Fraga, F. Lopes, J. I. Túnez, M. H. Cassini, P. Majluf, S. Cárdenas-Alayza, H. J. Pavés, E. A. Crespo, N. García, R. Loizaga de Castro, A. R. Hoelzel, M. Sepuìlveda, C. Olavarrýìa, V. H. Valiati, R. Quiñones, M. J. Peìrez-Álvarez, P. H. Ott, and S. L. Bonatto. 2017. Ancient female philopatry, asymmetric male gene flow, and synchronous population expansion support the influence of climatic oscillations on the evolution of South 
American sea lion (Otaria flavescens). PloS One 12:e0179442.

Diniz-Filho, J. A. F., R. D. Loyola, P. Raia, A. O. Mooers, and L. M. Bini. 2013. Darwinian shortfalls in biodiversity conservation. Trends Ecology Evol 28:689-95.

Dirzo, R., and A. Miranda. 1990. Contemporary neotropical defaunation and forest structure, function, and diversity - a sequel to John Terborgh. Conserv Biol 4:444-7.

Dirzo, R., E. Mendoza, and P. Ortíz. 2007. SizeØrelated differential seed predation in a heavily defaunated Neotropical rain forest. Biotropica 39:355-62.

Ekblom, R., and J. Galindo. 2011. Applications of next generation sequencing in molecular ecology of non-model organisms. Heredity 107:1-15.

Escalante, A. E., L. J. Barbolla, S. Ramírez-Barahona, and L. E. Eguiarte. 2014. The study of biodiversity in the era of massive sequencing. Revista Mexicana de Biodiversidad 85:1249-64.

Frankham, R. 2008. Genetic adaptation to captivity in species conservation programs. Mol Ecol 17:325-33.

Frankham R., J. D. Ballou, and D. A. Briscoe. 2002. Introduction to conservation genetics. Cambridge University Press, Cambridge, Massachusetts, Estados Unidos.

Fraser, D. J., and L. Bernatchez. 2001. Adaptive evolutionary conservation: towards a unified concept for defining conservation units. Mol Ecol 10:2741-52.

Gomez, M. D., J. Coda, I. Simone, J. Martínez, F. Bonatto, A. R. Steinmann, and J. Priotto. 2015. Agricultural land-use intensity and its effects on small mammals in the central region of Argentina. Mammal Res 60:415-23.

García-Alaniz, N., E. Naranjo, and F. F. Mallory. 2010. Hair-snares: A non-invasive method for monitoring felid populations in the Selva Lacandona, Mexico. Tropical Conservation Science 3:403-11.

Ghimire, K. B., and M. P. Pimbert. 2013. Social change and conservation. Routledge, New York, New York, Estados Unidos.

Gomes Rocha, R., J. Justino, Y. L. R. Leite, and L. P. Costa. 2015. DNA from owl pellet bones uncovers hidden biodiversity. Systematics and Biodiversity 13:403-12.

González, S., and J. M. Barbanti Duarte. 2007. Non invasive methods for genetic analysis applied to ecological and behavioral studies in Latino-America. Rev Bras Zootecn 36:89-92.

Goossens, B., and M. W. Bruford. 2009. Non-invasive genetic analysis in conservation. Pp. 167-201 en G. Bertorelle, M. W. Bruford, H. C. Hauffe, A. Rizzoli and C. Vernesi (eds.). Population genetics for animal conservation. Cambridge University Press, Cambridge, Massachusetts, Estados Unidos.

Grattarola, F., S. González, and M. Cosse. 2015. A novel primer set for mammal species identification from feces samples. Conserv Genet Resour 7:57-9.

Gudynas, E., and A. Acosta. 2011. La renovación de la crítica al desarrollo y el buen vivir como alternativa. Utopía y Praxis Latinoamericana 16:71-83.

Gudynas, E. 2003. Ecología, economía y ética del Desarrollo Sostenible. Ediciones ABYA-YALA, Quito, Ecuador.

Guichón, M. L., M. Borgnia, C. Fernández Righi, G. H. Cassini, and M. H. Cassini. 2003. Social behaviour of coypus (Myocastor coypus) in the Argentinean pampas. J Mammal 84:169-77.

Güneralp, B., and K. C. Seto. 2013. Futures of global urban expansion: uncertainties and implications for biodiversity conservation. Environ Res Lett 8:014025.

Hartl, D. L., and A. G. Clark. 1998. Principles of population genetics. Third edition. Sinauer Associates Inc., Sunderland, Massachusetts, Estados Unidos.

Harvey, C. A., O. Komar, R. Chazdon, B. G. Ferguson, B. Finegan, D. M. Griffith, M. Martínez-Ramos, H. Morales, R. Nigh, L. Soto-Pinto, M. Van Breugel, and M. Wishnie. 2008. Integrating agricultural landscapes with biodiversity conservation in the mesoamerican hotspot. Conserv Biol 22:8-15.

Hebert, L., S. K. Darden, B. V. Pedersen, and T. Dabelsteen. 2011. Increased DNA amplification success of non-invasive genetic samples by successful removal of inhibitors from faecal samples collected in the field. Conserv Genet Resour 3:41-3.

Iyengar, A. 2014. Forensic DNA analysis for animal protection and biodiversity conservation: A review. J Nat Conserv 22:195-205.

Jiménez-García, L., G. Sánchez-Rojas, O. Villarreal, H. Bernal, and D. Jiménez-García. 2014. Agroecosystems management and biodiversity loss in an intensification gradient in traditional agriculture in Mexico. American-Eurasian J Agric and Environ Sci 14:407-20.

Jorge, M. L. S. 2008. Effects of forest fragmentation on two sister genera of Amazonian rodents (Myoprocta acouchy and Dasyprocta leporina). Biol Conserv 141:617-23.

Kelt, D. A., and P. L. Meserve. 2014. Status and challenges for conservation of small mammal assemblages in South America. Biological Reviews 89:705-22.

Lindenmayer, D. B., and H. A. Nix. 1993. Ecological principles for the design of wildlife corridors. Conserv Biol 7: 627-30.

Ljungqvist, M., M. Åkesson, and B. Hansson. 2010. Do microsatellites reflect genome-wide genetic diversity in natural populations? A comment on Väli et al. 2008. Mol Ecol 19:851-5.

Luikart, G., N. Ryman, D. A. Tallmon, M. K. Schwartz, and F. W. Allendorf. 2010. Estimation of census and effective population sizes: the increasing usefulness of DNA-based approaches. Conserv Genet 11:355-73.

Maturrano, H., M. J. Aguilar, D. Krüger, I. Chávez, A. Rosadio, and J. C. Wheeler. 2012. Optimización de una técnica 
para la extracción de ADN de heces de vicuña (Vicugna vicugna mensalis). Revista de Investigaciones Veterinarias del Perú 23:369-76.

Marín, J. C., C. E. Saucedo, P. Corti, and B. A. González. 2009. Application of DNA forensic techniques for identifying poached guanacos (Lama guanicoe) in Chilean Patagonia. J Forensic Sci 54:1073-6.

Medan, D., J. P. Torretta, K. Hodara, B. Elba, and N. H. Montaldo. 2011. Effects of agriculture expansion and intensification on the vertebrate and invertebrate diversity in the Pampas of Argentina. Biodivers Conserv 20:3077-100.

Menon, S. 2014. Biodiversity informatics - Big data for biodiversity conservation and ecological forecasting. 2014 Presentations. Grand Valley State University, Allendale, Michigan, Estados Unidos.

Mittermeier R. A., N. Myers, J. B. Thomsen, G. A. B. da Fonseca, and S. Olivieri. 1998. Biodiversity hotspots and major tropical wilderness areas: approaches to setting conservation priorities. Conserv Biol 12:516-20.

Moritz, C. 1994. Defining 'evolutionarily significant units' for conservation. Trends Ecol Evol 9:373-5.

Nardelli, M., J. I. Túnez, D. Centrón, and M. H. Cassini. 2011. Técnicas de muestreo no invasivas aplicadas al estudio genético de mamíferos. Interciencia 36:404-11.

Northridge, S. P. 1991. An updated world review of interactions between marine mammals and fisheries. FAO Fisheries Technical Papers, Roma, Italia.

Novo, M. 2009. La educación ambiental, una genuina educación para el desarrollo sostenible. Revista de Educación 195-217.

Ojasti, J., and F. Dallmeier. 2000. Manejo de fauna silvestre neotropical. Smithsonian Institution/MAB Program, Washington D.C., Estados Unidos.

Oliveira, C. G., F. A. Gaiotto, M. A. Costa, and R. A. Martínez. 2011. Molecular genetic analysis of the yellow-breasted capuchin monkey: recommendations for ex situ conservation. Genet Mol Res 10:1471-1478.

Panasci, M., W. B. Ballard, S. Breck, D. Rodríguez, L. D. Densmore, D. B. Wester, and R. J Baker. 2011. Evaluation of fecal DNA preservation techniques and effects of sample age and diet on genotyping success. J Wildlife Manage 75 : 1616-24.

Periago, M. E., V. Chillo, and R. A. Ojeda. 2015. Loss of mammalian species from the South American Gran Chaco: empty savanna syndrome? Mammal Rev 45:41-53.

Perrin, W. F., B. Wursig, and J. G. M. Thewissen. 2009. Encyclopedia of Marine Mammals. Second edition. Academic Press, Londres, Inglaterra.

Petit, E., and N. Valiere. 2006. Estimating population size with noninvasive captureØmarkПrecapture data. Conserv Biol 20:1062-1073.

Pierson, J. C., S. R. Beissinger, J. G. Bragg, D. J. Coates, J. G. B. Oostermeijer, P. Sunnucks, N. H. Schumaker, M. V. Trotter, and A. G. Young. 2015. Incorporating evolutionary processes into population viability models. Conserv Biol 29:755-64.

Primack, R. B. 2002. Essentials of Conservation Biology. Third edition. Sinauer Associates, Sunderland, Massachusetts, Estados Unidos.

Rieseberg, L., T. Vines, and N. Kane. 2011. Editorial - 20 years of Molecular Ecology. Mol Ecol 20:1-21.

Ripperger, S. P., M. Tschapka, E. K. Kalko, B. Rodriguez-Herrera, and F. Mayer. 2013. Life in a mosaic landscape: anthropogenic habitat fragmentation affects genetic population structure in a frugivorous bat species. Conserv Genet 14:925-34.

Rodgers, T. W., and J. E. Janečka. 2013. Applications and techniques for non-invasive faecal genetics research in felid conservation. European journal of wildlife research 59:1-16.

Rodríguez, J. P., J. A. Simonetti, and A. Premoli. 2005. Conservation in austral and neotropical America: Building scientific capacity equal to the challenges. Conserv Biol 19:969-72.

Rodríguez Rodríguez, I., and P. Sanhueza Martínez. 2014. ¿Es racional fomentar el crecimiento económico? Polis (Santiago) 13:499-520.

Ruiz-García, M., M. I. Castillo, D. Álvarez, J. Gardeazabal, L. M. Borrero, D. M. Ramírez, L. Carrillo, F. Nassar, and H. Gálvez. 2007. Estudio de 14 especies de primates platirrinos (Cebus, Saimiri, Aotus, Saguinus, Lagothrix, Alouatta y Ateles), utilizando 10 loci microsatélites: análisis de la diversidad génica y de la detección de cuellos de botella con propósitos conservacionistas. Orinoquia 11:19-37.

Ruiz-García, M., N. Leguizamón, C. Vásquez, K. Rodríguez, and M. I. Castillo. 2010. Métodos genéticos para la reintroducción de monos de los géneros Saguinus, Aotus y Cebus (Primates: Cebidae) decomisados en Bogotá, Colombia. Rev Biol Trop 58:1049-67.

Runge, J. P., M. C. Runge, and J. D. Nichols. 2006. The role of local populations within a landscape context: Defining and classifying sources and sinks. Am Nat 167:925-38.

Ryder, O. A. 1986. Genetic investigations: tools for supporting breeding programme goals. International Zoo Yearbook 24:157-62.

Ryman, N., and F. Utter. 1986. Population genetics and fishery management. The Blackburn Press, Caldwell, New Jersey, Estados Unidos.

Sanches, A., P. M. Tokumoto, W. A. Peres, F. L. Nunes, M. S. Gotardi, C. S. Carvalho, C. Pelizzon, T. G. Godoi, and M. Galetti. 2012. Illegal hunting cases detected with molecular forensics in Brazil. Invest Genet 3:17-21.

Selig, E. R., W. R. Turner, S. Troëng, B. P. Wallace, B. S. Halpern, K. Kaschner, B. G. Lascelles, K. E. Carpenter, and R. A. Mittermeier. 2014. Global priorities for marine biodiversity conservation. PloS One 9:e82898. 
Sepúlveda, M., M. J. Pérez, W. Sielfeld, D. Oliva, L. R. Durán, L. Rodríguez, V. Araos, and M. Buscaglia. 2007. Operational interaction between South American sea lions Otaria avescens and artisanal (small-scale) fishing in Chile: Results from interview surveys and on-board observations. Fish Res 83:332-40.

Sauvé, L. 1999. La educación ambiental entre la modernidad y la posmodernidad: en busca de un marco educativo de referencia integrador. Tópicos 1:7-27.

Suzán, G., A. Armién, J. N. Mills, E. Marcé, G. Ceballos, M. Ávila, J. Salazar-Bravo, L. Ruedas, B. Armién, and T. L. Yates. 2008. Epidemiological considerations of rodent community composition in fragmented landscapes in Panama. J Mammal 89:684-90.

Taberlet, P., L. P. Waits, and G. Luikart. 1999. Noninvasive genetic sampling: look before you leap. Trends Ecol Evol 14:323-7.

Taft, H. R. 2012. Neutral markers, quantitative genetics and the use of statistics to inform conservation. Tesis doctoral. Universidad de California, Riverside, California, Estados Unidos.

Teta, P., A. Formoso, M. Tammone, D. C. de Tommaso, F. J. Fernández, J. Torres, J., and U. F. Pardiñas. 2014. Micromamíferos, cambio climático e impacto antrópico: ¿Cuánto han cambiado las comunidades del sur de América del Sur en los últimos 500 años? Therya 5:7-38.

Trigila, A. P., J. J. Gómez, M. H. Cassini, and J. I. Túnez. 2016. Genetic diversity in the Neotropical river otter, Lontra longicaudis (Mammalia, Mustelidae), in the Lower Delta of Parana River, Argentina and its relation with habitat suitability. Hydrobiologia 768:287-98.

Trinca, C. S., C. F. Jaeger, and E. Eizirik. 2013. Molecular ecology of the Neotropical otter (Lontra longicaudis): noninvasive sampling yields insights into local population dynamics. Biol J Linn Soc 109:932-48.

Túnez, J. I., M. L. Guichón, D. Centrón, A. Henderson, C. Callahan, and M. H. Cassini. 2009. Kinship and social organisation in coypus of Argentinean pampas. Mol Ecol 18:147-55.

Túnez, J. I., and L. Pimper. 2014. Marine mammals in southern South America: Biology, current status and conservation. Pp. 175-212 en A. S. Muñoz, C. M. Götz and E. R. Roca (eds.). Neotropical and Caribbean aquatic mammals Perspectives from archaeology and conservation biology. Nova Publishers, New York, New York, Estados Unidos.

Utrera, A., G. Duno, B. A. Ellis, R. A. Salas, N. de Manzione, C. F. Fulhorst, R. B. Tesh, and J. N. Mills. 2000. Small mammals in agricultural areas of the western llanos of Venezuela: community structure, habitat associations, and relative densities. J Mammal 81:536-48.

Vaz-Ferreira, R. Arctocephalus australis (Zimmermann), South American fur seal. 1982. Mammals in the Seas. FAO Fisheries Series 4:497-508.

Väli, Ü., A. Einarsson, L. Waits, and H. Ellegren. 2008. To what extent do microsatellite markers reflect genome-wide genetic diversity in natural populations? Mol Ecol 17:3808-17.

Viglizzo, E. F., F. C. Frank, L. V. Carreño, E. G. Jobbágy, H. Pereyra, J. Clatt, D. Pincén, and M. F. Ricard. 2011. Ecological and environmental footprint of 50 years of agricultural expansion in Argentina. Glob Change Biol 17:959-73.

Vitousek, P. M., H. A. Mooney, J. Lubchenco, and J. M. Melillo. 1997. Human domination of Earth's ecosystems. Science 277:494-9.

Waits, L. P., and D. Paetkau. 2005. Noninvasive genetic sampling tools for wildlife biologists: a review of applications and recommendations for accurate data collection. J Wildlife Manage 69:1419-33.

Wang, G., N. Thompson Hobbs, F. J. Singer, D. S. Ojima, and B. C. Lubow. 2002. Impacts of climate changes on elk population dynamics in Rocky Mountain National Park, Colorado, USA. Climatic Change 54:205-23. 